\title{
Literature Review Tentang Pendidikan Kesehatan Untuk Meningkatkan Pengetahuan Personal Hygiene Menstruasi Pada Remaja
}

\author{
Lilis Purwaningsih ${ }^{1 *}$, Isyti'aroh ${ }^{2}$, Windha Widyastuti ${ }^{3}$ \\ ${ }^{1,2,3}$ Program Studi Diploma Tiga Keperawatan, Universitas Muhammadiyah Pekajangan \\ Pekalongan, Indonesia \\ *email: lilispurwaningsihpml12@gmail.com
}

\begin{abstract}
Good understanding of menstrual hygiene management (MHM) is essential for women since uterus is susceptible to infection. Insufficient understanding of MHM may lead yound women to various problems such as unpleasant vaginal odour, Leukorrhea, and Urinary Tract Infections (UTI). Health education is an effort to provide information about health in order to change people behavior to achieve better quality of life. The purpose of this study was to determine the improvement of young women understanding of MHM before and after being given health education. This study was a literature review of three articles taken from the Google Scholar with "young women", "personal hygiene", and "menstruation" as the keywords, in the form of fulltext articles, and published during 2012-2020. The total number of the respondents from the three articles was 170 . The results showed that after being given health education, the respondents' understanding level of MHM increased from $7 \%$ $55 \%$. In conclusion, health education could improve young women's understanding level of MHM. Therefore, health care providers are suggested to conduct health education to improve the understanding of MHM to young women.
\end{abstract}

Keywords: menstruation, knowledge, young women

\begin{abstract}
Abstrak
Personal hygiene yang baik pada saat menstruasi sangat diperlukan karena rahim mudah terkena infeksi. Dampak yang ditimbulkan apabila remaja putri tidak memperhatikan hygiene pada daerah kewanitaannya, antara lain muncul bau yang tidak sedap, keputihan dan berkembangnya bakteri yang dapat menimbulkan infeksi saluran kemih. Literature review ini bertujuan untuk mengetahui perbedaan pengetahuan remaja tentang personal hygiene sebelum dan sesudah diberikan pendidikan kesehatan. Desain karya tulis ilmiah berupa literature review. Hasil penelitian terdapat perbedaannilai pengetahuan baik sebelum dilakukan pendidikan kesehatan adalah $7 \%$ dan sesudah pendidikan kesehatan nilai pengetahuan baik menjadi 55\%. Simpulannya pendidikan kesehatan dapat meningkatkan pengetahuan remaja mengenai personal hygiene ketika menstruasi.Saran bagi tenaga kesehatan agar melakukan pendidikan kesehatan untuk meningkatkan pengetahuan remaja mengenai personal hygiene ketika menstruasi.
\end{abstract}

Kata kunci: Menstruasi; pengetahuan; remaja

\section{Pendahuluan}

Personal hygiene merupakan suatu tindakan menjaga kebersihan dan kesehatan yang bertujuan untuk meningkatkan derajat kesehatan perorangan baik fisik maupun psikis[1].Kebersihan perorangan berperan penting dalam status perilaku kesehatan seseorang agar terhindar dari adanya gangguan pada fungsi alat reproduksi. Saat menstruasi pembuluh darah yang ada didalam rahim sangat mudah terinfeksi. 


\section{Prosiding Seminar Nasional Kesehatan Lembaga Penelitian dan Pengabdian Masyarakat Universitas Muhammadiyah Pekajangan Pekalongan}

Kebersihan alat kelamin harus lebih dijaga karena kuman mudah sekali masuk yang dapat menyebabkan infeksi saluran reproduksi[2].

Hygiene pada saat menstruasi merupakan komponen personal hygiene yang memegang peranan penting dalam status perilaku kesehatan seseorang, termasuk menghindari adanya gangguan pada fungsi alat reproduksi [3].Kebersihan perorangan berperan penting dalam status perilaku kesehatan seseorang agar terhindar dari adanya gangguan pada fungsi alat reproduksi.Saat menstruasi pembuluh darah yang ada didalam rahim sangat mudah terinfeksi.Kebersihan alat kelamin harus lebih dijaga karena kuman mudah sekali masuk yang dapat menyebabkan infeksi saluran reproduksi [4].

Hasil penelitian tentang pengetahuan personal hygiene menstruasi dari 54 responden yang memiliki pengetahuan kurang sebanyak 48 responden [5].Berdasarkan studi pendahuluan pada bulan Juni 2015 di SMPN 30 Bandung dengan cara wawancara langsung kepada 10 siswi didapatkan hasil bahwa 4 siswi dapat memahami pengetahuan vulva hygiene dan perilaku hygine pada saat menstruasi dengan mengganti pembalut 4 jam sekali, sedangkan 6 siswi belum memahami pengetahuan vulva hygiene dan perilaku hygine pada saat menstruasi secara benar [6].

Upaya yang dilakukan untuk meningkatkan pengetahuan adalah pendidikan kesehatan. Pendidikan kesehatan adalah aktifitas-aktifitas yang berupaya menginformasikan kepada individu tentang karakteristik dan penyebab kesehatan atau penyakit, serta tingkat risiko yang berkaitan dengan perilaku gaya hidup yang dimiliki oleh individu tersebut. Pendidikan kesehatan berupaya untuk memotivasi individu dalam menerima suatu proses perubahan perilaku dengan secara langsung mempengaruhi [7].

Penelitian lain menunjukkan bahwa pengetahuan kurang mengenai personal hygiene sebelum diberikan pendidikan kesehatan sebanyak 15 responden dan pengetahuan baik sebanyak 15 responden [8]. Setelah diberikan pendidikan kesehatan remaja putri yang memiliki pengetahuan kurang sebanyak 4responden dan pengetahuan baik meningkat menjadi26 responden.Hasil penelitian tersebut menunjukkan bahwa terdapat hubungan pendidikan kesehatan dengan pengetahuan remaja mengenai personal hygiene ketika menstruasi.

Berdasarkan permasalahan diatas penulis tertarik untuk mengangkat topik "Pendidikan Kesehatan Untuk Meningkatkan Pengetahuan Personal Hygiene Menstruasi Pada Remaja" yang berdasarkan literature review sebagai topik karya tulis ilmiah. Penulis berharap agar pembaca mengetahui apakah pendidikan kesehatan dapat meningkatkan pengetahuan personal hygiene menstruasi pada remaja.

\section{Metode}

Metode yang digunakan dalam penelitian ini adalah literature review. Pengumpulan data dilakukan dengan mencari artikel jurnal sejumlah tiga dengan topik yang sama yang diambil dari laman pencarian google scholar yang terbit di laman jurnal resmi yang terdapat ISSN, menggunakan uji yang sama pada ketiga artikel, terbit dalam 10 tahun terakhir, fulltext, dan memaparkan struktur penulisan publikasi penelitian serta melakukan analisis data. Ketiga artikel yang direview metodologinya sama. Ketiga artikel menggunakan data kategorik (baik, cukup dan kurang).Tingkat 


\section{Prosiding Seminar Nasional Kesehatan Lembaga Penelitian dan Pengabdian Masyarakat Universitas Muhammadiyah Pekajangan Pekalongan}

pengetahuan baik jika nilainya $>75 \%$, cukup $56-74 \%$, dan kurang jika nilainya < $55 \%$.

\section{Hasil dan Pembahasan}

\section{Hasil}

Hasil dari analisa distribusi frekuensi data demografi yang mencantumkan karakteristik umur terdapat di artikel pertama dan ketiga.

Tabel 3.1 Karakteristik Responden Berdasarkan Usia, Pendidikan dan Sumber Informasi

\begin{tabular}{lcc}
\hline Karakteristik & Frekuensi & Presentase \% \\
\hline Artikel 1 dan 3 & $\mathrm{n}=140$ & \\
Umur & & \\
12 tahun & 15 & 11 \\
13 tahun & 37 & 26 \\
14 tahun & 29 & 21 \\
15 tahun & 23 & 16 \\
16 tahun & 18 & 13 \\
17 tahun & 18 & 13 \\
Artikel 1 & $\mathrm{n}=108$ & \\
Pendidikan & & \\
SMP & 49 & 45,4 \\
SMA & 59 & 54,6 \\
Artikel 1 & & \\
Sumber Informasi & 37 & 34,3 \\
Iklan & 11 & 10,2 \\
Guru & 28 & 25,9 \\
Orang Tua & 32 & 29,6 \\
Tenaga Kesehatan & &
\end{tabular}

Berdasarkan artikel 1 dan 3 tentang gambaran karakteristik responden sebagian besar berusia 13 tahun sebanyak 37 responden (26\%). Pendidikan responden berdasarkan artikel 1 yang paling banyak adalah SMA sebesar 59 responden (54,6\%). Sumber informasi yang tercantum di artikel 1 paling banyak diperoleh dari iklan sebesar 37 responden (34,3\%).

Tabel 3.2.Distribusi Frekuensi Pengetahuan Responden Sebelum dan Sesudah

\begin{tabular}{|c|c|c|c|c|}
\hline \multicolumn{5}{|c|}{ Intervensi $(n=170)$} \\
\hline \multirow[t]{2}{*}{ Variabel } & \multicolumn{2}{|c|}{ Sebelum Intervensi } & \multicolumn{2}{|c|}{ Sesudah Intervensi } \\
\hline & $n$ & $\%$ & $n$ & $\%$ \\
\hline \multicolumn{5}{|c|}{ Pengetahuan } \\
\hline Baik & 12 & 7 & 94 & 55 \\
\hline Cukup & 53 & 31 & 27 & 16 \\
\hline Kurang & 105 & 62 & 49 & 29 \\
\hline
\end{tabular}

Berdasarkan tabel diatas terdapat peningkatan pengetahuan sebelum dan sesudah dilakukan pendidikan kesehatan personal hygiene menstruasi pada remaja dengan peningkatan pengetahuan baik dari $7 \%$ menjadi $55 \%$. 


\section{Prosiding Seminar Nasional Kesehatan 2021 Lembaga Penelitian dan Pengabdian Masyarakat Universitas Muhammadiyah Pekajangan Pekalongan}

\section{Pembahasan}

Ketiga artikel menyebutkan bahwa remaja mengalami peningkatan pengetahuan baik dari prosentase $7 \%$ menjadi $55 \%$. Hasil analisis data ketiga artikel menunjukkan pengetahuan kurang pada remaja tentang personal hygiene ketika menstruasi sebelum dilakukan pendidikan kesehatan dan peningkatan pengetahuan baik sesudah dilakukan pendidikan kesehatan.Pendidikan kesehatan merupakan salah satu cara yang digunakan untuk meningkatkan pengetahuan remaja. Pengetahuan merupakan aksi seseorang terhadap reaksi dari stimulus, dapat diartikan semua kegiatan atau aktivitas manusia yang diamati secara langsung maupun tidak langsung [9].

Pada ketiga artikel yang direview, pendidikan kesehatan sama-sama dilakukan pada remaja putri.Remaja sebagai masa peralihan atau transisi dari masa anak-anak menuju masa dewasa yang berjalan antara umur 12 tahun sampai 21 tahun dan ditandai dengan adanya perubahan aspek fisik, psikis, dan psikososial [10]. Pada masa remaja terjadi berbagai perubahan yang cukup signifikan baik secara fisik, biologis, mental, dan emosional serta psikososial [11].Personal hygiene yang kurang menyebabkan terjadinya penyakit, maka perlu diberikan upaya-upaya kesehatan masyarakat dalam menjaga hygiene [12].Salah satu penyebab dari penularan penyakit adalah kurangnya pengetahuan dan sikap dalam menjaga personal hygiene.Faktorfaktor yang mempengaruhi seseorang melakukan personal hygiene yaitu faktor ekonomi yang berkaitan dengan sarana dan prasarana dalam melakukan perawatan diri, budaya yang berkaitan dengan mitos-mitos yang diyakini oleh remaja dalam perawatan diri dan pengetahuan [13]. Sumber informasi yang kurang menyebabkan pengetahuan yang rendah dan akan berdampak pada sikap dan tindakan remaja putri. Sehingga diperlukan sumber informasi melalui pendidikan kesehatan yang bersifat inovatif dan menarik [14].

Pendidikan kesehatan adalah aktifitas-aktifitas yang berupaya menginformasikan kepada individu tentang karakteristik dan penyebab kesehatan atau penyakit, serta tingkat risiko yang berkaitan dengan perilaku gaya hidup yang dimiliki oleh individu tersebut. Pendidikan kesehatan berupaya untuk memotivasi individu dalam menerima suatu proses perubahan perilaku dengan secara langsung mempengaruhi [15].Pengetahuan yang didapatkan sesudah diberikan pendidikan kesehatan diharapkan dapat berpengaruh terhadap perilaku remaja.Pendidikan kesehatan yang dilakukan bertujuan untuk menjadikan kesehatan sebagai suatu yang bernilai di masyarakat [16]. Hasil review artikel tentang "Pendidikan Kesehatan Media Audiovisual Lebih Efektif untuk Meningkatkan Pengetahuan Siswa tentang Kesehatan Reproduksi" telah membuktikan bahwa pendidikan kesehatan melalui media audiovisual meningkatkan pengetahuan baik sebesar 64,3\% [17].

Terdapat perbedaan dari ketiga artikel yaitu media yang digunakan.Pada artikel 1 menggunakan media ceramah dan diskusi. Metode ceramah termasuk dalam metode diktatik atau satu arah, pendidik yang aktif dan peserta biasanya pasif [18]. Metode ceramah ekonomis dan efektif untuk menyampaikan informasi dan pengertian. Ketika memberikan ceramah dalam satu waktu dan tempat, responden akan diberikan informasi yang sama.Metode ceramah sering digunakan, terlebih untuk massa dengan jumlah yang banyak. Pendidikan kesehatan dalam bentuk ceramah atau penyuluhan 


\section{Prosiding Seminar Nasional Kesehatan Lembaga Penelitian dan Pengabdian Masyarakat Universitas Muhammadiyah Pekajangan Pekalongan}

dapat meningkatkan pengetahuan, sikap dan memungkinkan juga untuk mengubah perilaku masyarakat [19].Pada artikel 2 menggunakan media audiovisual.Media audiovisual merupakan media yang menggabungkan gambar dan suara yang dapat dinikmati oleh indera pandang dan indera dengar secara bersamaan [20].Penggunaan media audiovisual dalam pendidikan kesehatan menyebabkan responden menyerap pengetahuan lebih banyak karena melibatkan dua indera terbesar dalam penyerapan informasi, yaitu indera penglihatan dan pendengaran [21].Pada artikel 3 media yang digunakan yaitu ceramah dan tanya jawab. Metode ceramah merupakan penyampaian pesan/informasi secara verbal atau lisan [22].Keberhasilan seseorang dalam menyampaikan informasi melalui pendidikan kesehatan dengan menggunakan metode ceramah tidak lepas dari beberapa faktor yang mempengaruhinya antara lain faktor kemampuan dari pemberi informasi (pemateri) dan responden itu sendiri yang masih tergolong usia muda atau remaja awal sehingga masih memiliki motivasi dan rasa ingin tahu yang tinggi dalam mencari informasi baru [23].

Hasil dari ketiga penelitian tersebut dapat disimpulkan bahwa pendidikan kesehatan dapat meningkatkan pengetahuan pada remaja tentang personal hygiene ketika menstruasi. Hal ini sejalan dengan penelitian tentang "Pengaruh Pendidikan Kesehatan dengan Media Video Terhadap Tingkat Pengetahuan Remaja Tentang Personal Hygiene Saat Menstruasi Di SMPN 1 Gamping", menunjukkan hasil bahwa terdapat peningkatan pengetahuan tentang personal hygiene saat menstruasi sebelum dan sesudah diberikan pendidikan kesehatan dengan nilai $p=0,000(p<0,05)[24]$.

\section{Kesimpulan}

Berdasarkan literature review diatas dapat disimpulkanbahwa pendidikan kesehatan dapat meningkatkan pengetahuan remaja mengenai personal hygiene ketika menstruasisebelum dan sesudah diberikan pendidikan kesehatan dengan nilai pengetahuan baik dari $7 \%$ meningkat menjadi 55\%. Saran bagi tenaga kesehatan agar melakukan pendidikan kesehatan untuk meningkatkan pengetahuan remaja mengenai personal hygiene ketika menstruasi. Dan diharapkan remaja putri supaya lebih memperhatikan kebersihan diri pada saat menstruasi dengan cara membersihkan alat kelamin dari depan ke belakang, mengganti pembalut setiap 3-4 jam, membuang bekas pembalut dengan benar, dan mengganti celana apabila sudah terkena noda.

\section{Referensi}

[1] L. Isroin dan S. Andarmoyo, Personal hygiene konsep, proses, dan aplikasi dalam praktik keperawatan.Yogyakarta: Graha ilmu. 2012.

[2] N.A. Putri dan A. Setianingsih, "Hubungan pengetahuan dan sikap terhadap perilaku personal hygiene menstruasi" Jurnal ilmu kesehatan masyarakat, vol. 5, no.1, pp. 15-23, 2016.

[3] L. Handayani, E. Kurnaesih, dan Sundari, "Pengaruh edukasi melalui media video dan leaflet terhadap perilaku personal hygiene pada masa menstruasi remaja di SMPN 2 Toili di Kec.Mailong Kab Banggai"Jurnal of Aafiyah health research, vol. 1, no.1, pp. 19-27, 2020. 


\section{Prosiding Seminar Nasional Kesehatan 2021 Lembaga Penelitian dan Pengabdian Masyarakat Universitas Muhammadiyah Pekajangan Pekalongan}

[4] N.A. Putri dan A. Setianingsih, "Hubungan pengetahuan dan sikap terhadap perilaku personal hygiene menstruasi" Jurnal ilmu kesehatan masyarakat, vol. 5, no.1, pp. 15-23, 2016.

[5] D. Susanti dan A. Lutfiyati, "Hubungan pengetahuan remaja putri dengan perilaku personal hygiene saat menstruasi" Jurnal kesehatan samodra ilmu, vol.11, no. 2, pp. 166-172, 2020.

[6] Maidartati, S. Hayati, dan L.A. Nurhida, "Hubungan pengetahuan dengan perilaku vulva hygiene pada saat menstruasi remaja putri"Jurnal ilmu keperawatan, vol. 4, no. 1, pp. 50-57, 2016.

[7] Asniar, H. Kamil,dan P. Mayasari, "Pendidikan dan promosi kesehatan" , 2020.

[8] D.N. Pramudianti, Mirawati, dan F. Aulia,"Pendidikan kesehatan tentang personal hygiene pada remaja putri di SMP 1 Muhammadiyah Banjarmasin"Jurnal pengabdian masyarakat"' vol. 2, no. 1, pp. 31-35, 2020.

[9] D.N. Pramudianti, Mirawati, dan F. Aulia, "Pendidikan kesehatan tentang personal hygiene pada remaja putri di SMP 1 Muhammadiyah Banjarmasin"Jurnal pengabdian masyarakat" vol. 2, no. 1, pp. 31-35, 2020.

[10] H.E. Dewi, Memahami perkembangan fisik remaja. Yogyakarta: Gosyen publishing. 2012.

[11] Miswanto, "Pentingnya pendidikan kesehatan reproduksi dan seksualitas pada remaja"Jurnal studi pemuda, vol 3, no. 2, pp. 111-121, 2014.

[12] L. PH, E. Yulianto, dan Hermanto, "Pengaruh pendidikan personal hygiene terhadap tingkat pengetahuan dan sikap masyarakat"Jurnal keperawatan komprehensif, vol. 4, no. 1, pp. 1-6, 2018.

[13] F. Yumaeroh, dan D. Susanti, "Pengaruh pendidikan kesehatan dengan media video terhadap tingkat pengetahuan remaja tentang personal hygienesaatmenstruasi di SMP N 1 Gamping" Media ilmu kesehatan, vol. 8, no. 3, pp. 203-209, 2019.

[14] L. Handayani, E. Kurnaesih, dan Sundari,"Pengaruh edukasi melalui media video dan leaflet terhadapperilaku personal hygienepada masa menstruasi remaja di SMPN 2 Toili di Kec.Mailong Kab Banggai"Jurnal of Aafiyah health research, vol. 1 , no. 1 , pp. 19-27, 2020.

[15] L. Isroin dan S. Andarmoyo, Personal hygiene konsep, proses, dan aplikasi dalam praktik keperawatan.Yogyakarta: Graha ilmu. 2012.

[16] Widyawati, Buku ajar pendidikan dan promosi kesehatan. 2020.

[17] E.R. Regina, dan R. Delima, "Pendidikan kesehatan media audiovisual lebih efektif untuk meningkatkan pengetahuan siswa tentang kesehatan reproduksi"Media ilmu kesehatan, vol. 2, no. 1, pp. 40-45, 2013. 


\section{Prosiding Seminar Nasional Kesehatan $\mathbf{2 0 2 1}$ Lembaga Penelitian dan Pengabdian Masyarakat Universitas Muhammadiyah Pekajangan Pekalongan}

[18] S,N. Prabasari, danH.A. Putri, "Perbedaan penerapan pengaruh pendidikan metode ceramah dan diskusi kelompok terhadap tingkat pengetahuan seks pranikah remaja Kelas X SMA N2 Banguntapan" DSpace Repository, pp. 1-9, 2017.

[19] A.H. Ngestiningrum, Nuryani, dan A. Setiyani, "Efektifitas metode "index card match" dan ceramah dalam meningkatkan pengetahuan, sikap, dan perilaku personal hygiene saat menstruasi pada remaja"2-Trik tunas-tunas riset kesehatan, vol. 7, no. 2, pp. 114-120, 2017.

[20] I. Wijayanti, "Pengaruh media audiovisual terhadap perkembangan emosi anak kelompok B di TK Pertiwi I Gondang Sragen tahun pelajaran 2013/2014" SKRIPSI Universitas Muhammadiyah Surakarta, 2013.

[21] N.R. Sasmita, Ilmi. N.R, dan Huriati, "Peningkatan pengetahuan tentang cuci tangan melalui pendidikan kesehatan dengan media audiovisual"Journal of Islamic nursing, vol.2, no. 2, pp. 43-51, 2017.

[22] W. Pujiati, Ernawati, dan Daratullaila,"Pendidikan kesehatan tentang menstruasi terhadap tingkat kecemasan menghadapi menarche pada siswi sekolah dasar"Mediasains: jurnal ilmiah ilmu-ilmu kesehatan,vol. 13, no. 1, pp. 50-58, 2015.

[23] U. Panggabean, "Pengaruh pendidikan kesehatan terhadap pengetahuan remaja putri tentang personal hygiene saat menstruasi di SMP Negeri 14 Pontianak"Jurnal proners, vol. 3, no. 1, 2017.

[24] F. Yumaeroh, dan D. Susanti, " Pengaruh pendidikan kesehatan dengan media video terhadap tingkat pengetahuan remaja tentang personal hygienesaat menstruasi di SMP N 1 Gamping" Media ilmu kesehatan, vol. 8, no. 3, pp. 203209, 2019. 